\title{
RISE OF SEA LEVEL AND THE SINKING ISLANDS OF SUNDARBAN REGION: A STUDY OF MOUSUNI ISLAND IN INDIA
}

\author{
Madhusudan Karmakar, Parthapratim Dey and Madhushree Roy \\ Assistant Professors in Geography \\ Maynaguri College, Jalpaiguri, West Bengal, India \\ Email: madhukarmakar.2008@rediffmail.com
}

\begin{abstract}
Mousuni, a human habitat island in the Indian Sundarban and located on the southernmost tip of Bengal, is under constant threat of inundation caused by sea level rise. It has been hugely affecting the lives and livelihood of the communities living around the coastal region of the Island. The main objective of the present study is to explore the erosional level and sinking of Mousuni Island and to find out the impact of it on the livelihood of the people. Based on the primary and secondary data the findings of the present study show that if the erosional activity of engulfing water of Bay of Bengal continues the Mousuni Island will sink within 80 to 100 years. Submergence of the island increases the vulnerability of the poor people of the island and reducing capacity to cope with the existing problem.
\end{abstract}

Key words: Erosion Level, Impact Studies, Sea Level, Sinking Island

\section{Introduction}

Climate change is a major concern across the globe and this has been directly affecting the coastal communities of many countries. Sundarban- the southern part of West Bengal, India is a living example of it. Sundarban islands like Sagar, Namkhana, Jambudwip, Ghoramara and Mousuni have been affected by the coastal tidal erosion due to increased level of sea water. Ghoramara and Jambudwip Island have already been deserted. Ghoramara is a vanishing island with more than 50 percent of its land already eroded out since 1969 (Jana et al., 2012), while Mousuni is facing the threats of erosion at its southern tip (WWF, 2010). The present study first explores the overall coastal erosion and inundation problem of different human habitat islands of Sundarban region and then it will proceed to study the nature of erosional and inundation problem of Mousuni island. After mentioning the impact of the present erosional problem the study highlights some preventive measures to save the human habitation and their livelihood.

\section{Objectives}

The present study embraces the following objectives.

- To know the nature of erosional level and sinking of Mousuni Island

- To explore the impact of livelihood of the people

- To suggest protective measures for preventing the island from flooding

\section{Study Area}

Mousuni Island lies in Namkhana block in Kakdwip subdivision of South 24 Parganas district of West Bengal, India. There are seven gram panchayats in Namkhana block and Mousuni is one of these. It is a deltaic island spread on Bay of Bengal. Muri Ganga River in West \& NorthWestern fringe, the eastern part is bounded by Pitt's Creek while the southern part is fringed by the Bay of Bengal (Fig-1). According to 2011 Census the total population of the island is 22073. The island consists of four villages, such as Baliara, Bagdanga, Kusumtala and Mousuni. The total area of the Island is $27.1 \mathrm{sq} . \mathrm{km}$.

\section{Literature Review}

There are several works and research activities on the rising of sea water level and sinking of islands since it has been a serious hazard faced by people in different parts of the world. Bandyopadhyay (1997, 2000, 2004, 2007 \& 2009) carries out several works on Sundarban region. In his work of 1997 he mentions natural environmental hazards and their management 
of Sagar Island. Gopinath (2010) in his work focuses an account of the critical coastal issues of Sagar Island of Sundarban region. Hazra et.al (2002) in their work mentions the sea level and associated changes in the Sundarbans. Jana et. al (2012) in their work presents a morphological change study of Ghoramara Island using Multi Temporal Satellite data. In this study erosion problem of Ghoramara island has been highlighted. Mukhopadhyay, (2009) in his study gives an account of the socio-economic aspects of embankment people of Sundarban region emphasizing on social justice.

Figure 01: Location Map of the Study Area

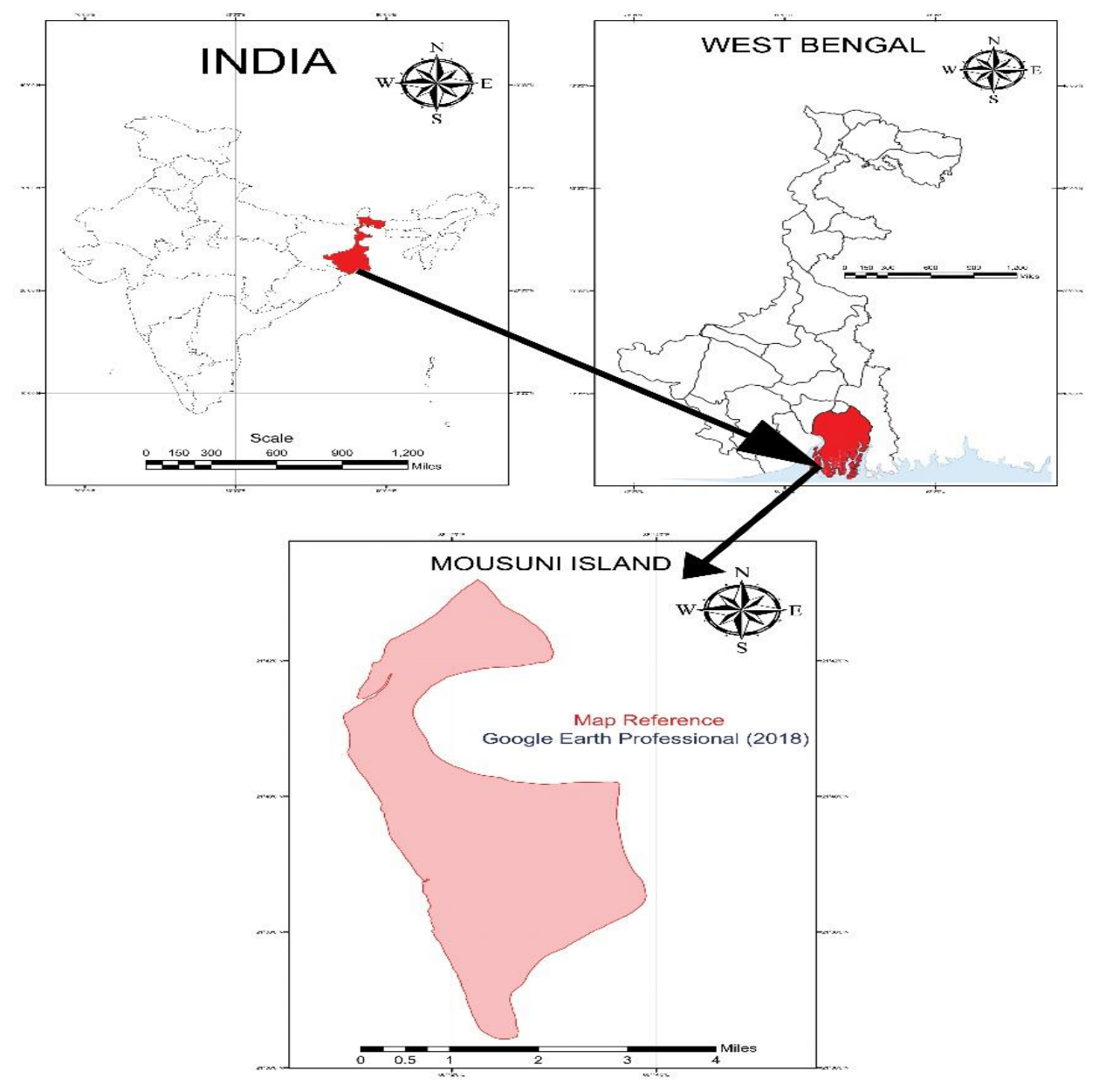

\section{Methodology}

The present study is based on both primary and secondary data generated through researchers' field survey. In the first phase the secondary data have been collected. Data on erosional level of some islands of Sundarban like Sagar, Namkhana, Mousuni, Ghoramara and Jambudwip and the changes in the land use patterns and land cover classes in Sunderbans between 2001 and 2009 have been collected from the School of Oceanographic Studies, Jadavpur University (2010). Loss of area of Mousuni Island from 1977 to 2018 has been picked up by analysing the images of Landsat 2 MMS (1977), Landsat 5 TM (1989, 1997 and 2007) and Google Earth Professional (2018). In this case Arc GIS 10.4 is used. On the basis of the time series analysis of the erosional level of Mousuni island a prediction has been done for Mousuni Island. Loss of area of Mousuni Island from 1977 to 2018 has been shown by different time intervals. Emphasis has been given on the district gazetteers, district statistical handbook, articles, proper published works, research based data, census report, development plans and on the monographs available on the region. On the basis of the secondary data and information, a literature review is made by the authors for the meaningful understanding of the problem of present study. The second phase is related to the collection of primary data. For obtaining the information on the present erosional and sinking problem and its impact on island dwellers a random sample survey of 80 households was conducted at two mouzas of Mousuni Island i.e., Baliara and Kusumtala village from $20^{\text {th }}$ October to $29^{\text {th }}$ October in 2018 . These two villages have been selected for random household survey as the inhabitants of these villages are severely affected by the coastal erosion and inundation problem. Qualitative and 
quantitative sampling schedule interviews of inhabitants were conducted to understand the ground level concerns and priorities.

\section{RESULTS AND DISCUSSION}

\section{Nature of Sea Level Rise and Sinking of Area i9n Sundarban Region}

Sundarbans has been identified as one of the vulnerable areas in the climate change context due to its ecological fragility (Jagtap, 2007; Erwin, 2009). Coastal erosion, prolonged inundation and soil salinisation have been discussed vividly in different literatures (Hazra et al., 2002; Ghosh et al., 2003; Jayappa et al., 2006; Gopinath, 2010). Rising sea levels and river dynamics such as strong tidal surges put together cause the breach of embankments, which leads to coastal flooding and destruction of lives and livelihood of the community? Global sea level rise is estimated to be just two millimetres a year and the levels in the Sundarbans delta are rising 3.14 by $\mathrm{mm}$. a year. A one metre rise in sea level could inundate an estimated 17 per cent of Bangladesh and take the entire Sundarbans with it (Hingorani \& Raman, 2009). The river embankments in the Sundarban islands are constructed by mud. The embankments are supposed to protect the islands from getting inundated during high tide condition, since the average height of these islands in most of the places is below the mean sea level. The embankments are in a dilapidated condition and are no longer suitable with the changing river dynamics. In this context the erosional level and sinking of some islands of Sundarban are mentioned in table-1.

Table 01: Sinking of some islands of Sundarban from 2001 to 2009

\begin{tabular}{|l|c|c|c|c|}
\hline Islands & $\begin{array}{c}\text { Area in 2001 } \\
\text { (sq. } \mathbf{~ k m . )}\end{array}$ & $\begin{array}{c}\text { Area in 2009 } \\
\text { (sq. } \mathbf{~ k m . )}\end{array}$ & $\begin{array}{c}\text { Loss or sinking of } \\
\text { area (sq. } \mathbf{~ k m . )}\end{array}$ & $\begin{array}{c}\text { Percent of Loss or } \\
\text { sinking area }\end{array}$ \\
\hline Sagar & 244.434 & 239.091 & 5.343 & 2.18 \\
\hline Namkhana & 150.155 & 145.488 & 4.667 & 3.10 \\
\hline Mousuni & 28.283 & 27.643 & 0.64 & 2.28 \\
\hline Ghoramara & 5.339 & 4.564 & 0.774 & 14.52 \\
\hline Jambudwip & 6.242 & 4.979 & 1.263 & 20.19 \\
\hline
\end{tabular}

Source: S.Hazra, K. Samanta, A. Mukhopadhyay \& A. Akhand (2010). Temporal change Detection study of Sundarban, School of Oceanographic Studies, Jadavpur University

\section{Sinking of Mousuni Island}

According to 2011 Census the total population of the Island is 22073. The island consists of four villages, such as Baliara, Bagdanga, Kusumtala and Mousuni. 2011 Census shows that Baliara has a population of 8672, Bagdanga 4160, Kusumtala 5663 and Mousuni 3578. Of these erosional problem is much active at Baliara and Kusumtala village. These two villages occupy 64.94 percent population of the total population of Mousuni Island. The western coast of Baliara and southern and western parts of Kusumtala are much affected by the engulfing water. People living near these parts are always in a state of panic due to constant threat of water intrusion and flood in the high tide situation. The rising sea level, continuous and rapid erosion of the coastline encourage the sinking of the island that have forced the inhabitants of the area to relocate further inland in this fragile island. From the obtained image of Landsat 2 MMS(1977), Landsat 5 TM $(1989,1997,2007)$ and Google Earth Professional (2018) it is found that 24.51 percent area of the Mousuni Island has been lost from 1977 to 2018. Sea level rise is responsible for this aggression of erosional activity of Bay of Bengal. The North western and western parts of the Island are much affected as this portion is open to the angry wavy tidal actions of Bay of Bengal. The Eastern part is eroded less as this portion is not open to Bay of Bengal and it is surrounded by calm Pitt's creek. The percentage loss of area of Mousuni Island from 1977 to 1989 was 4.18 percent and it reached to maximum (9.73 percent) during the period of 1997-2007. The period from 2007 to 2018 experiences almost the same trend of loss of Island area i.e., 8.75 percent (Fig.3). In fact the erosional activity and related sinking of Mousuni Island have been aggressive since Aila storm of 2009. Aila was merely a wakeup call. The real danger is yet to strike. Fig. 2 substantiates the fact the increasing submergence of the Mousuni Island. If this erosional activity of engulfing water of Bay of Bengal continues the Mousuni Island will sink completely within 80 to100 years and its position will be like the fate of Lohachara, Suparibhanga (Bedford), New Moore Island and adjacent Ghoramara and Jambudwip Island. 


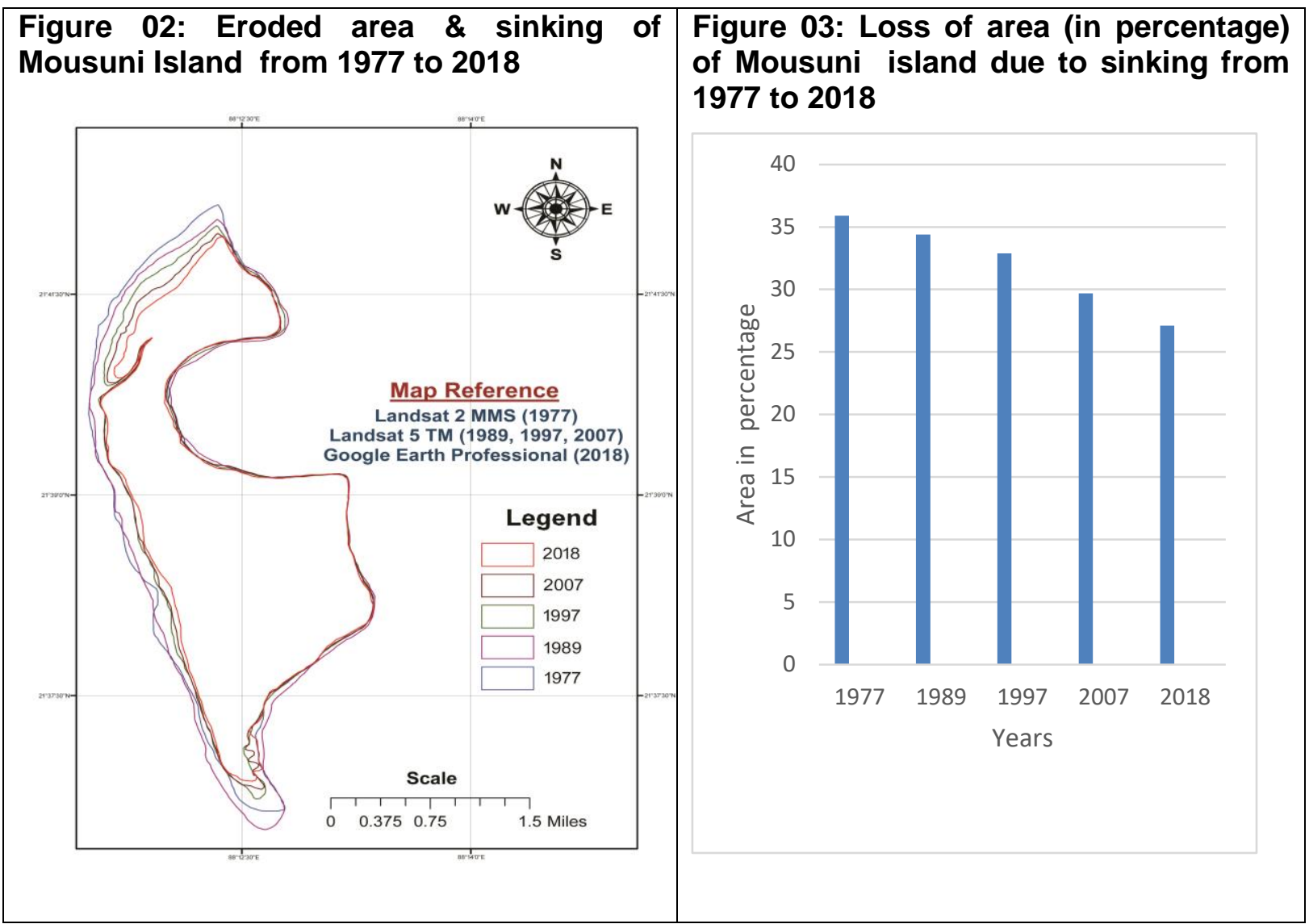

Sources: Landsat 2 MMS (1977), Landsat 5 TM (1989, 1997, 2007) Google Earth Professional (2018)

\section{Impact Studies}

- According to Mousuni Gram Panchayet Office about 2,200 families have been displaced or affected severely by the rising sea in Mousuni. The household survey of Baliara and Kusumtala- the most affected villages of Mousuni Island reveals that 54.84 percent people have lost their lands and the percentage of people who lost their houses is 38.71 percent.

- The survey also reflects that the fishing activity has been affected much (40.38 percent) due to erosion and engulfing of water. As the sea is engulfing the Island the fishing fields have been changed and so fishing activity has been affected much.

- Again due to invasion of saline water into the agricultural lands the farming activity has also been affected. The field survey also shows that 72 percent people have lost their agricultural lands due to salinity. The agriculture dependent community then takes up odd jobs as daily wage labourers due to lack of livelihood facilities and many people migrate to other areas in search of jobs. Thus migration rate is found to be high in the island i.e., 62 percent as is recorded in the present household survey.

- According to the field survey report 88 percent people say that the local Panchayat or Block or District administration do not take any step for the present erosion problem. Leaders come and give assurance to build embankments in the erosion prone areas but as the time passes their assurance fades away.

- Agriculture is the major livelihood of the four villages of the island. Due to high tides, cyclones and storm surges, and problems of water stagnation, agriculture fields become highly saline, thus, turning them sterile for years.

\section{Measures for Saving the Inhabitants of Mousuni Island}

Some immediate steps have to be carried out to mitigate the present problem of Mousuni Island. These include-

- Embankment building along the north western part, western and south eastern part is a crucial step to save the Island from sea aggression.

- Shore protections with mangrove plantations and road network development can help to reduce the vulnerability of the Island. It has been observed that strong coastal vegetation is 
amongst most reliable natural defences of an island at times of ocean induced flooding, strong winds and against coastal erosion (DIRAM Report,2008).

- If government is unable to solve the erosional problem of Mousuni Island through the above steps the govt. should at least remove all the erosion-affected island dwellers to other areas with proper rehabilitation programmes as it is done for Tuvalu islanders of Eastern Pacific ocean. Thus it is the proper time to act on humanitarian point of view.

\section{Findings}

Sea level rise aggravated erosions have found a beachhead in different parts of Sundarban region. Mousuni Island has been affected much by this problem and its western, northern and southern parts have been gradually engulfing or sinking. If this erosional activity of engulfing water of Bay of Bengal continues the Mousuni Island will sink within 80 to 100 years. Submergence of the island increases the vulnerability of the poor people of Mousuni Island and reducing capacity to cope with the existing problem. Large scale outmigration has been very active in the island as there is no alternative way of livelihood of the island dwellers.

\section{Conclusion}

The present situation on the ground of Mousuni Island is nothing but a short of an ecological disaster. So there is an urgent need of State and Central government assistance along with international attention. Therefore it is now proper time to pay much attention to the sinking problem of Mousuni and other human habitat islands of Sundarban region.

\section{References}

1. Detailed Island Risk Assessment in Maldives (DIRAM Report, 2008) Volume III: Detailed Island Reports, G. Dh. Thinadhoo - Part 1. Disaster Risk Management Programme UNDP Maldives.

2. Erwin, K.L. (2009) Wetlands and global climate change: the role of wetland restoration in a changing world, Wetlands Ecol Manage, 17, 71-84

3. Gopinath, G. (2010) Critical coastal issues of Sagar Island, east coast of India, Env. Monitor. Assest, 160, 555-561. (Published online, 2009).

4. Hazra S, Ghosh, T. Dasgupta, R. Sen, G.K. (2002) Sea Level and Associated Changes in the Sundarbans, Science and Culture, 68 (9-12), 309 - 321.

5. Hingorani, S \& Raman, L (2009) Lessons from Aila - cyclones in the Sundarbans, whirlwinds in the corridors of power. Sanctuary Asia, Vol. XXIX. No. 4. August 2009.

6. Jagtap, T.G. (2007) Response and adaptability of mangrove habitats from Indian subcontinent to changing climate, Ambio, 36 (4), 328 - 334.

7. Jana, A. Sheena, S. Biswas, A. (2012) Morphological Change Study of Ghoramara island, Eastern India using Multi Temporal Satellite data, Research J. of Recent Sc. , 1(10), 72 81.

8. WWF (2010) Sundarbans: Future Imperfect - Climate Adaptation Report, WWF (India) Report. Pp. 28

9. Department of Agriculture and Horticulture. (Undated) Reconstruction and Rehabilitation Reports of Agriculture/Horticulture Departments of South 24 Parganas. West Bengal.

10. Jalais, A. (2004) People and Tigers in the Sundarbans. Unpublished Ph.D. dissertation. London School of Economics, University of London.

11. Mukherjee, N \& Siddique, G. (2018) Climate change and vulnerability assessment in Mousuni Island: South 24 Parganas District, India.Spatial Information Research, Volume 26, Issue 2, pp 163-174|

12. Mukhopadhyay, A. (2009) 'On the wrong side of the fence: embankment people and social justice in the Sundarbans' in Pradip Kumar Bose and Samir Kumar Das (eds.) Social Justice and Enlightenment: West Bengal. New Delhi: Sage. 